\title{
Urban Green and Blue Infrastructure Simulation in a Changing Climate from Microclimate to Energy Consumption: A Case study in Alexandria, Egypt
}

\author{
Ahmed Ayad ${ }^{1}$, Mohammad Fahmy ${ }^{2}$, Wael Kamel ${ }^{1}$ \\ ${ }^{1}$ Construction and Building Engineering Department, College of Engineering and Technology, Arab \\ Academy for Science, Technology and Maritime Transport, Alexandria, Egypt \\ ${ }^{2}$ Architecture Engineering Department, Military Technical College, Cairo, Egypt
}

\begin{abstract}
Vegetation and water bodies, known as green and blue infrastructure can be an important strategy for shaping sustainable and resilient cities. In this study, the effect of green and blue infrastructure on the cooling energy use of residential buildings in an arid hot desert climate is investigated using a coupled simulations methodology combining microclimate, building energy and climate change simulations. Results revealed that, in comparison with a baseline scenario (asphalt road), the use of blue infrastructure alone has the highest energy savings $(8.12 \%)$ followed by combining green and blue infrastructures $(6.73 \%)$ and green infrastructure alone $(4.78 \%)$. These savings are impacted by climate change, water cover percentage and the mixed-mode cooling strategy used in the building with a negligible impact for the canopy cover percentage. The study recommends that blue infrastructure should be the first option in planning a sustainable and resilient city.
\end{abstract}

\section{Introduction}

As cities grow, challenges like: increased energy use, climate change $\ldots$ etc. are causing adverse environmental impacts and deteriorating the quality of life which makes the transition towards a sustainable city that reduces its impact on the environment while being resilient to natural and man-made stresses a must. Such a transition would require less dependence on energy (Heijden, 2014). To lessen that dependence, special attention needs to be given to the building sector since it is considered the largest energy consuming sector worldwide with three-quarters of that consumption attributed to residential buildings (Dulac et al., 2013). One of the possible strategies to reduce the energy use of buildings is the utilization of vegetation and water bodies, known as Green and Blue Infrastructure (GBI) (Perini, 2016).

Two main methods are applied in studying the effects of GBI on the urban microclimate and building's energy use, field measurements/experiments and modelling/simulations (Wang et al., 2014; Bartesaghi Koc et al., 2018). The modelling/simulations method can enable comparative analyses of different scenarios which would be difficult to conduct using field measurements/experiments method that is largely constrained by the characteristics of the case study selected for measurement or the experiment's setup.
Among the studies that applied the modelling/simulations method, Morakinyo et al. (2018) estimated that GI (different tree species) can reduce cooling energy use, based on the greenery coverage ratio within $500 \times 500 \mathrm{~m}^{2}$ domain, between $1500 \mathrm{kWh}$ and $3000 \mathrm{kWh}$ per typical summer day in Hong Kong. The study used ENVI-met model for simulating the urban microclimate and an empirical equation for estimating the cooling energy use. Fahmy et al. (2017) investigated the effect of GI (trees, green roofs and green walls) on the residential buildings' energy use in two different climatic zones in Egypt in present and future by applying a coupled simulations methodology using ENVI-met microclimate model and EnergyPlus building energy model. The climate change projections, used to predict the future climate, were based on the Third Assessment Report (TAR) of the Intergovernmental Panel on Climate Change (IPCC). The study showed that GI can reduce energy use by $10 \%$ up to $21.3 \%$ depending on the site and the effects of climate change. Radhi et al. (2015) showed that the presence of green spaces coupled with water bodies (GBI) lowered the cooling energy demand of AMWAJ Islands in Bahrain with no investigation of the exact amount of reduction. The study used a validated CFD model (PHOENICS) for the microclimate simulation and an empirical equation for estimating the cooling energy demand (based on cooling degree-days).

However, in the aforementioned studies, the effect of BI on the building's energy use was unclear and needs further investigations in order to understand the effects of $\mathrm{BI}$ alone or in combination with GI. Moreover, there is a need to understand how the water cover percentage can change that effect. This lack of scientific evidence for the effects of BI was also confirmed in a comprehensive review paper by Bartesaghi Koc et al. (2018). Furthermore, four other gaps of knowledge can be identified from the above-reviewed studies. First, the impact of changing the canopy cover percentage on the effect of GI was not investigated especially in combination with BI. Second, the investigation of climate change impact was limited to the GI and was based on relatively outdated climate change projections from IPCC TAR which was conducted back in 2001 (IPCC, 2001). Third, the use of dynamic building energy simulations was limited and empirical equations were used instead which can yield errors as they neglect the thermal dynamics of the building. Finally, the effect of GBI on the heat transfer due to the outside air that enters the building 
for ventilation was not investigated. This is especially important in the case of buildings that combine airconditioning and natural ventilation (mixed-mode cooling) where the mixed-mode cooling strategy used can significantly affect the energy use of the building as shown in the simulation study conducted by Daly (2002).

The current study aims to simulate the urban microclimatic changes induced by GBI and its effect on the annual cooling energy use of residential buildings in present and future climates with different mixed-mode cooling strategies applied at the building scale. The study focuses on green spaces (a mixture of grass and trees) as an example of GI and a water canal as an example of BI and is applied to a real case study in Alexandria, Egypt which is characterized by an arid hot desert climate (BWh) according to Köppen-Geiger climate classification system (Kottek et al., 2006). The contributions of the study can be summarized in the following points:

- It applies coupled simulations methodology by combining three different simulation models (microclimate, building energy and climate change) into one workflow.

- It investigates the effect of GBI in present and future climates using the climate change projections of the latest assessment report from IPCC, the Fifth Assessment Report (AR5) (IPCC, 2014).

- It investigates the effects of BI alone and in combination with GI.

- It investigates the relationship between the cooling energy use reduction effect of GBI and the mixedmode cooling strategy applied at the building scale.

\section{Methods}

A modelling-based approach combining the microclimate model ENVI-met, the building energy model EnergyPlus (using DesignBuilder software) and the climate change models of IPCC AR5 (using WeatherShift tool), in a socalled coupling methodology, was used in the current study since there is no holistic model available that can simulate the three aspects (microclimate, energy use and climate change) simultaneously (Fahmy et al., 2014).

ENVI-met is a prognostic three-dimensional microclimate model capable of simulating the surfaceplant-air interactions in the urban environment (ENVImet, 2018). It was validated using field measurements in various studies, e.g. Fahmy et al. (2019). EnergyPlus is an energy analysis and thermal load simulation program that is widely used to simulate building's energy use. It is extensively tested and validated using industry-standard methods (e.g. IEA BESTEST) (EnergyPlus, 2018a). The Graphical User Interface (GUI) for EnergyPlus used in this study is DesignBuilder which is one of the most known EnergyPlus interfaces (DesignBuilder, 2018). Finally, to simulate the climate change, the study used the output of the General Circulation Models (GCM) from IPCC AR5 through the 'WeatherShift' tool (Dickinson and Brannon, 2016) which downscales the coarse resolution output of the GCMs to a finer resolution (both temporary and spatially) that can be used in building energy simulations. The coupling of the models (and tools) used in the study was done in four main stages (as shown in Figure 1) following the work of Fahmy et al. (2017) with some modifications:

- Stage 1: generating a projected future EnergyPlus Weather (EPW) file, using WeatherShift tool, from the original EPW file for the location of interest based on a specified emission scenario and future period.

- Stage 2: running the urban microclimate simulations using ENVI-met and then averaging the results using LEONARDO (a built-in ENVI-met tool). The boundary conditions of the ENVI-met model are either obtained from the original EPW file for the location of interest (when simulating the present climatic conditions) or from the projected future EPW file generated in Stage 1 (when simulating the future climatic conditions).

- Stage 3: using the averaged output from ENVI-met to create a modified (custom) EPW file.

- Stage 4: running the building energy simulations in EnergyPlus simulation engine (through its GUI DesignBuilder) using the custom weather file created in Stage 3.

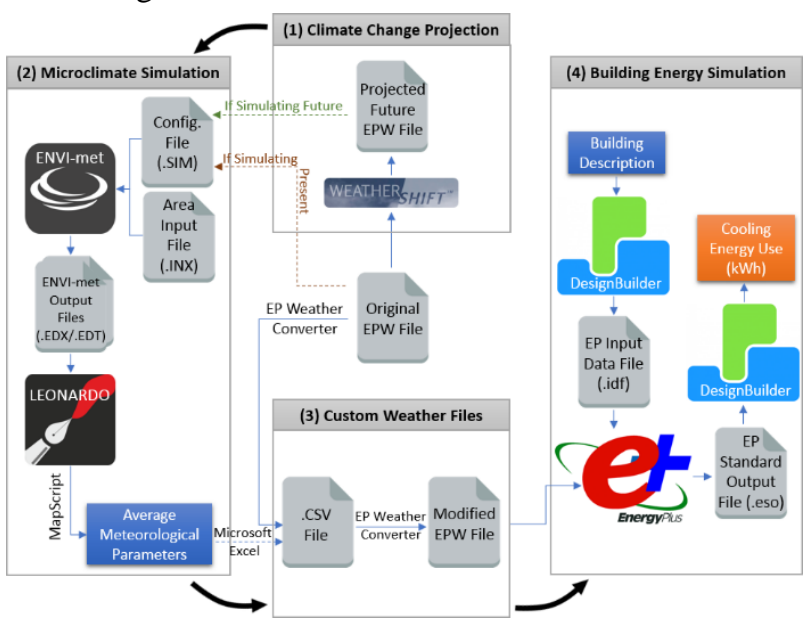

Figure 1: Flowchart for the coupling methodology showing the data exchanged between the different tools.

\section{Case Study}

An existing residential compound called "Ta'awenyat Smouha" located in Alexandria, Egypt $\left(31^{\circ} 12^{\prime} 32.63^{\prime \prime N}\right.$, $\left.29^{\circ} 57^{\prime} 15.03 " \mathrm{E}\right)$ was studied. This residential compound overlooks El-Mahmoudia canal which is currently under development and is planned to be covered by a highway while the stream of water will be diverted into a pipe culvert. The existence of a water canal and the ongoing developments of the site makes this residential compound a perfect match for the purpose of the current study because it makes it feasible to test different design alternatives that utilize GBI and investigate the effect of these alternatives on the urban microclimate and the energy use of surrounding residential buildings. As shown in Figure 7, eight design alternatives (simulation scenarios) in addition to a baseline scenario (scenario 0 ) 
were tested in the study. The eight design alternatives (scenarios) can be grouped into three groups:

- Group 1 (scenarios 1 and 2): which intends to investigate the effect of BI alone and how varying the water cover percentage can change that effect.

- Group 2 (scenarios 3, 4 and 5): which intends to investigate the effect of GI alone and how varying the canopy cover percentage can change that effect.

- Group 3 (scenarios 6, 7 and 8): which intends to investigate the combined effect of GI and BI with different canopy cover percentages.

The changes in each scenario are focused on the area of El-Mahmoudia canal and its two banks (highlighted in Figure 2) which is referred to as 'area under development' in the rest of the study and is around $38,628 \mathrm{~m}^{2}$ which represents $16.22 \%$ of the total site area $\left(238,140 \mathrm{~m}^{2}\right)$. The changes in the 'area under development' are based on the utilization of green spaces composed of trees and grass (referred to as 'GI'), a water canal (referred to as 'BI'), or combinations of green spaces and the water canal (referred to as 'GBI').

\section{Stage 1: Climate Change Projection}

Using the "WeatherShift" tool, a projected future EnergyPlus Weather (EPW) file was generated for Alexandria, for the period 2081-2100, based on its original EPW file available on EnergyPlus website (EnergyPlus, 2018b). The projection was performed based on the Representative Concentration Pathway (RCP) 8.5 which is one of the climate change projection scenarios used in IPCC AR5. The 8.5 means an addition of $8.5 \mathrm{~W} / \mathrm{m}^{2}$ or more of heating in 2100 compared to preindustrial levels (i.e. before 1750) (IPCC, 2014).

\section{Stage 2: Urban Microclimate Simulation}

The urban microclimate modelling process in ENVI-met involves the creation of two input files; an area file (to define the model's geometry and components) and a configuration file (to define the model's boundary conditions, biometeorology and building physics).

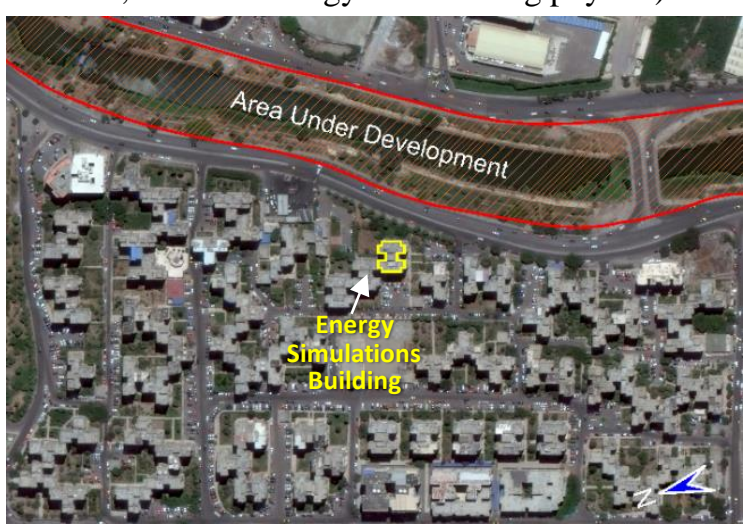

Figure 2: Satellite image for the case study site.

The area file was created based on a recent satellite image for the site (Figure 2) taken by DigitalGlobe's WorldView-3 Earth observation satellite with a resolution of $0.31 \mathrm{~m}$. Table 1 summarizes the main input parameters in the area file. All trees in the site were assumed to be Populus Alba which is commonly used in Egypt (Yasser,
2017) and is already available in ENVI-met library since investigating the effect of different tree species is outside the scope of the current study.

Table 1: ENVI-met main area file's parameter.

\begin{tabular}{|c|c|}
\hline \multicolumn{2}{|c|}{ Grids \& Rotation } \\
\hline No. of grids & $\mathrm{x}=196, \mathrm{y}=135, \mathrm{z}=21$ \\
\hline Grid size (m) & \multicolumn{1}{c|}{$108^{\circ} \mathrm{dz}=6$} \\
\hline Model rotation & \multicolumn{1}{c|}{ Model Elements } \\
\hline \multicolumn{2}{|c|}{ Heights according to a site survey. } \\
Buildings & $\begin{array}{l}\text { - Wall/roof properties are the same } \\
\text { used in the building energy model. }\end{array}$ \\
\hline Vegetation & $\begin{array}{l}\text { - Grass: 8 cm height } \\
\text { - Trees: Populus Alba } \\
\text { - Hedges: 2 m height }\end{array}$ \\
\hline Soil \& Surfaces & $\begin{array}{l}\text { loamy soil - sandy soil - asphalt - } \\
\text { concrete pavement - water }\end{array}$ \\
\hline
\end{tabular}

In the configuration file, the start and duration of the model run in addition to the boundary conditions are defined. Table 2 shows the model's boundary conditions which were determined based on the meteorological data provided in Alexandria's original EPW file for the present and from the output of WeatherShift tool for the future.

Table 2: ENVI-met model's boundary conditions.

\begin{tabular}{|c|c|c|}
\hline & Present & Future \\
\hline Initial temperature of atmosphere $\left({ }^{\circ} \mathrm{C}\right)$ & 21 & 28 \\
\hline Relative humidity in $2 \mathrm{~m}(\%)$ & 88 & 85 \\
\hline Specific humidity at model top $(\mathrm{g} / \mathrm{kg})$ & 13.78 & 20.38 \\
\hline Wind speed in $10 \mathrm{~m}$ above ground $(\mathrm{m} / \mathrm{s})$ & \multicolumn{2}{|c|}{3.35} \\
\hline Wind direction $(\mathrm{deg})$ & \multicolumn{2}{|c|}{317} \\
\hline
\end{tabular}

In order to simulate for the worst-case scenario, the start date of the simulation was determined to be the date where the worst outdoor thermal comfort conditions and highest cooling energy demand occur. By analysing the original EPW file of Alexandria in addition to historical monthly household electricity consumption data from the Egyptian Ministry of Electricity and Energy (CEIC Data, 2017), the simulation date was selected to be the $8^{\text {th }}$ of September. In order to increase the model's accuracy and reduce numerical errors, an initialization period is needed (called "spin-up phase") which can range from 1 hour up to 22 hours (Zhang et al., 2017). In this study, a 17-h spin-up phase was used and hence it was determined to run the model for 41 hours and only consider the results of the last 24 hours as a valid output. This resulted in starting the simulation at the $7^{\text {th }}$ of September at sunrise (06:00 AM).

\section{Stage 3: Custom Weather Files}

For every simulation scenario tested (shown in Figure 7), a custom weather file was created to be used in the energy simulation of that scenario with a total of 18 custom weather files for the 9 simulation scenarios (each scenario had two weather files to represent the present and future). Each custom weather file was created by editing the original EPW file of Alexandria and changing the values of: Dry Bulb Temperature, Dew Point Temp, Relative Humidity, Global Horizontal Radiation, Direct Normal Radiation, Diffuse Horizontal Radiation, and Wind Speed for the simulation date ( $8^{\text {th }}$ of September) based on the output from ENVI-met model. This output was extracted 
by averaging the values of the ENVI-met model grids surrounding the building used in the energy simulations for each meteorological parameter.

\section{Stage 4: Building Energy Simulation}

A twelve-story residential building, located $90 \mathrm{~m}$ away from the center of the 'area under development', was chosen for the energy simulations (Figure 2). The building has a symmetrical floor plan that contains four identical apartments each with an area of $75 \mathrm{~m}^{2}$ (Figure 3).

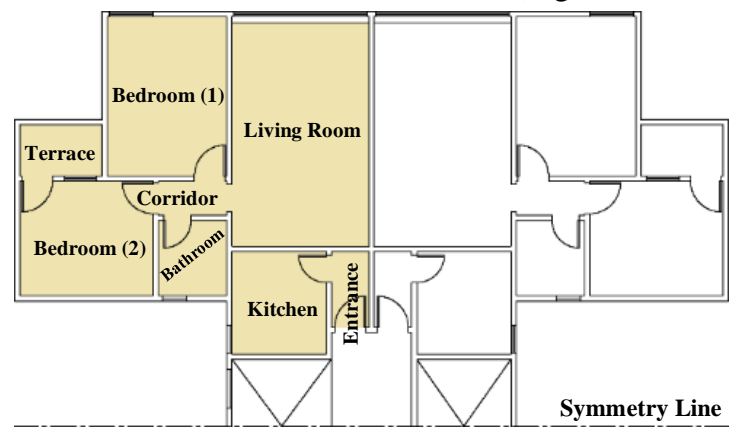

Figure 3: Half of the building's symmetrical floor plan.

Building envelope elements were retrieved from the Database of Egyptian Building Envelopes (DEBE, 2011) except for the walls and windows which were determined from site observations. The building envelope was assumed to have a medium airtightness. Only living rooms and bedrooms (a total of $62 \mathrm{~m}^{2}$ per apartment) were air-conditioned using a split $\mathrm{A} / \mathrm{C}$ unit set to $24{ }^{\circ} \mathrm{C}$ where the occupants adapted a mixed-mode cooling strategy by combining natural ventilation (operable windows) and air-conditioners which is a common practice in the Egyptian residential buildings (Attia et al., 2012). Mixedmode cooling can be classified into three types: concurrent, changeover, and zoned (Brager, 2006). In the current study, the effect of operating the air-conditioned zones in either concurrent $(\mathrm{A} / \mathrm{C}$ and natural ventilation work simultaneously in the same space and at the same time) or changeover (A/C and natural ventilation work in the same space but at different times) modes was investigated since both modes were reported, in previous studies, to be used in Egyptian residential buildings (Attia and Herde, 2009; Attia et al., 2012). The energy simulations were conducted for the same simulation date used in microclimate simulations ( $8^{\text {th }}$ of September).

\section{Models' Validation}

Since no meteorological field measurements were available for the site under study, the measurements from the nearest weather station to the site (WMO Station \#623180) were used in validating the ENVI-met model. These measurements were obtained for the simulation date ( $8^{\text {th }}$ of September) from Alexandria's original EPW file which reflects the typical weather conditions of Alexandria. Figure 4 shows a comparison between the measured and simulated air temperatures (an average for the whole simulated area) for the $8^{\text {th }}$ of September.

Three quantitative measures were calculated to statistically validate the output of ENVI-met model; coefficient of determination $\left(\mathrm{r}^{2}\right)$, Root Mean Squared Error (RMSE), and Willmott's index of agreement (d).

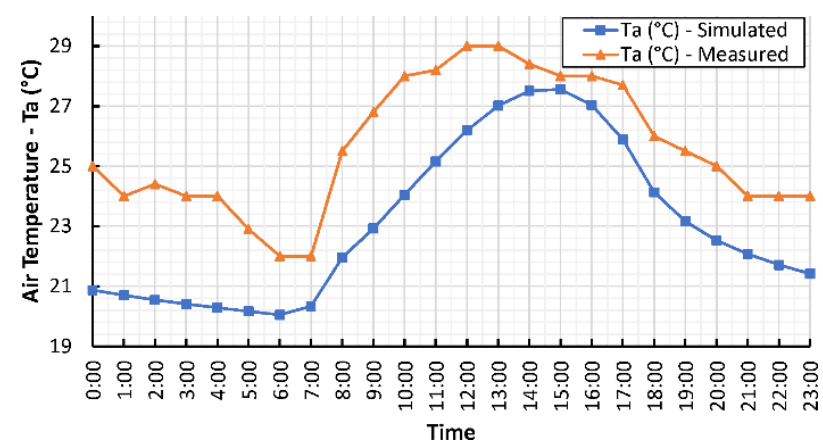

Figure 4: Hourly time series of measured and simulated average air temperatures at the $8^{\text {th }}$ of September.

These measures are widely used in the validation of urban microclimate simulation studies, e.g. Zhang et al. (2018) and Elwy et al. (2018). For a good model performance, RMSE should approach 0 while $\mathrm{r}^{2}$ and $\mathrm{d}$ should approach 1 (Zhang et al., 2018). In the current study, the $r^{2}$ for air temperature data was 0.85 which indicates a strong correlation between simulated and measured values where $85 \%$ of the total variance of measurements is explained by the model (Figure 5). The value of $d$ was equal to 0.74 which shows a good agreement between the measured and simulated values. The RMSE was equal to $2.77^{\circ} \mathrm{C}$ and represents the average error in the model and can be attributed to the measurements used in the validation since it was obtained from the weather station located in Alexandria (Nouzha) airport where the microclimate is very different from the site investigated in the study. This also might be the reason why the air temperatures reported by the station are higher than the model output as shown in Figure 4 which can be owed to the nature of the surfaces in the airport that are mainly asphalt with no vegetation.

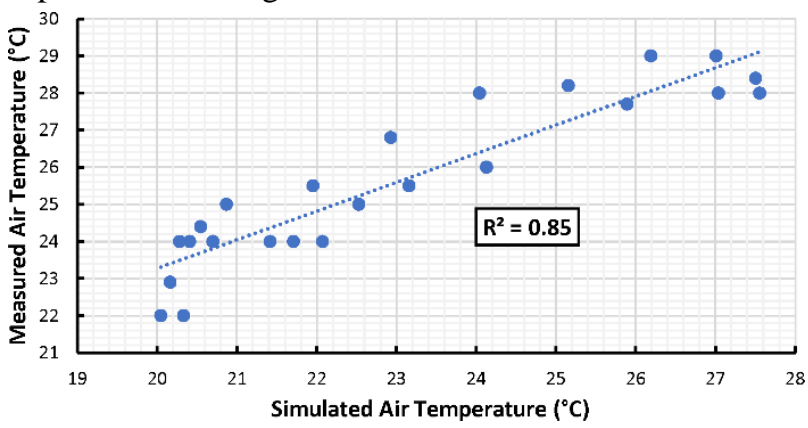

Figure 5: Scatterplot of measured vs. simulated hourly average air temperatures.

As for the building energy model, the validation was not possible because measurements for the building energy use were not available. However, the model used in the current study was developed using an accredited program (EnergyPlus) and hence its results are acceptable enough to be considered valid (Fumo, 2014). Also, the approach of energy modelling followed in the study is "comparative energy modelling" where the interest is on the percentage reduction in annual cooling energy use of different scenarios compared to a baseline scenario which makes the actual energy use in $\mathrm{kWh}$ of minor importance (IBPSA-USA, 2012). 


\section{Results and Discussion}

The results of the building energy simulations conducted for the $8^{\text {th }}$ of September were transformed into annual values using Cooling Degree-Hours (CDH) following the work of Day et al. (2003) which proposed a linear relationship between degree-days (and hence degreehours) and building energy use. The kWh per $\mathrm{CDH}$ was calculated from the output of each simulation scenario and then was used to calculate the annual cooling energy use based on the annual $\mathrm{CDH}$. The calculation of $\mathrm{CDH}$ was done, based on a base temperature of $23{ }^{\circ} \mathrm{C}$, using hourly dry- bulb temperature data from the original EPW file of Alexandria. The annual cooling energy use of the building in $\mathrm{kWh} / \mathrm{yr}$ was divided by the number of apartments (48 apartments) and apartment's conditioned floor area to calculate the annual cooling Energy Use Intensity (EUI) of the apartment in $\mathrm{kWh} / \mathrm{m}^{2}-\mathrm{yr}$.

\section{Energy Saving Potential of BI}

By analysing the results of group 1 simulation scenarios (S1 and S2), shown in Table 3, it appears that the presence of water in the urban environment can significantly reduce the annual cooling EUI of surrounding residential buildings with an average reduction of $8.12 \%$ and a maximum of $14.22 \%$.

Table 3: Simulation results for the BI scenarios.

\begin{tabular}{|c|c|c|c|c|}
\hline & Scenario & $\begin{array}{l}\text { Cooling EUI } \\
\left(\mathbf{k W h} / \mathrm{m}^{2}-\mathrm{yr}\right)\end{array}$ & $\begin{array}{c}\text { Cooling EUI } \\
\text { Savings } \\
\left(\mathbf{k W h} / \mathrm{m}^{2}-\mathbf{y r}\right)\end{array}$ & $\begin{array}{c}\text { \%age } \\
\text { Saving }\end{array}$ \\
\hline \multirow{8}{*}{ 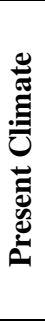 } & \multicolumn{4}{|c|}{ Changeover Mixed-Mode Cooling } \\
\hline & Baseline & 30.77 & - & - \\
\hline & S1 & 28.25 & 2.52 & $8.18 \%$ \\
\hline & S2 & 26.94 & 3.82 & $12.42 \%$ \\
\hline & \multicolumn{4}{|c|}{ Concurrent Mixed-Mode Cooling } \\
\hline & Baseline & 37.69 & - & - \\
\hline & S1 & 33.85 & 3.83 & $10.17 \%$ \\
\hline & S2 & 32.33 & 5.36 & $14.22 \%$ \\
\hline \multirow{8}{*}{ 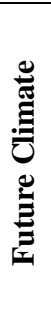 } & \multicolumn{4}{|c|}{ Changeover Mixed-Mode Cooling } \\
\hline & Baseline & 85.19 & - & - \\
\hline & S1 & 81.99 & 3.19 & $3.75 \%$ \\
\hline & $\mathrm{S} 2$ & 81.01 & 4.18 & $4.91 \%$ \\
\hline & \multicolumn{4}{|c|}{ Concurrent Mixed-Mode Cooling } \\
\hline & Baseline & 149.65 & - & - \\
\hline & S1 & 142.67 & 6.97 & $4.66 \%$ \\
\hline & S2 & 139.65 & 10.00 & $6.68 \%$ \\
\hline
\end{tabular}

This reduction is directly related to the water cover percentage where the results show that increasing the water cover percentage has a good potential for increasing savings in annual cooling EUI. In present climate, increasing the water cover from $47 \%$ (S1) to $100 \%$ (S2) (in the 'area under development') resulted in increasing the percentage saving by $4.24 \%$ and $4.05 \%$ in case of applying changeover and concurrent mixed-mode cooling strategies respectively. These increases were reduced in future climate where increasing the water cover from $47 \%$ (S1) to $100 \%$ (S2) (in the 'area under development') resulted in increasing the percentage saving by $1.16 \%$ and $2.02 \%$ in case of changeover and concurrent mixed-mode cooling respectively. It should be noted that the relationship between increasing the water cover and cooling EUI savings is non-linear as nearly doubling the water cover did not result in doubling the annual cooling EUI savings.

\section{Energy Saving Potential of GI}

The results of group 2 simulation scenarios (S3, S4 and S5), provided in Table 4, shows that GI can reduce the annual cooling EUI, on average, by $4.78 \%$ with a maximum reduction of $8.3 \%$.

Table 4: Simulation results for the GI scenarios.

\begin{tabular}{|c|c|c|c|c|}
\hline & Scenario & $\begin{array}{l}\text { Cooling EUI } \\
\left(\mathbf{k W h} / \mathbf{m}^{2}-\mathbf{y r}\right)\end{array}$ & $\begin{array}{c}\text { Cooling EUI } \\
\text { Savings } \\
\left(\mathbf{k W h} / \mathbf{m}^{2}-\mathrm{yr}\right)\end{array}$ & $\begin{array}{c}\text { \%age } \\
\text { Saving }\end{array}$ \\
\hline \multirow{10}{*}{ 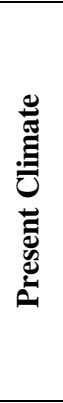 } & \multicolumn{4}{|c|}{ Changeover Mixed-Mode Cooling } \\
\hline & Baseline & 30.77 & - & - \\
\hline & S3 & 28.80 & 1.96 & $6.38 \%$ \\
\hline & S4 & 28.91 & 1.86 & $6.04 \%$ \\
\hline & S5 & 29.06 & 1.70 & $5.53 \%$ \\
\hline & \multicolumn{4}{|c|}{ Concurrent Mixed-Mode Cooling } \\
\hline & Baseline & 37.69 & - & - \\
\hline & S3 & 34.56 & 3.13 & $8.30 \%$ \\
\hline & S4 & 34.76 & 2.93 & $7.77 \%$ \\
\hline & S5 & 35.09 & 2.60 & $6.90 \%$ \\
\hline \multirow{10}{*}{ 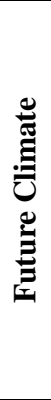 } & \multicolumn{4}{|c|}{ Changeover Mixed-Mode Cooling } \\
\hline & Baseline & 85.19 & - & - \\
\hline & S3 & 82.78 & 2.41 & $2.82 \%$ \\
\hline & S4 & 83.10 & 2.09 & $2.45 \%$ \\
\hline & S5 & 83.20 & 1.99 & $2.33 \%$ \\
\hline & \multicolumn{4}{|c|}{ Concurrent Mixed-Mode Cooling } \\
\hline & Baseline & 149.65 & - & - \\
\hline & S3 & 144.96 & 4.69 & $3.13 \%$ \\
\hline & S4 & 145.16 & 4.49 & $3.00 \%$ \\
\hline & S5 & 145.52 & 4.13 & $2.76 \%$ \\
\hline
\end{tabular}

By examining the results, it appears that decreasing the spacing between trees (increasing the canopy cover) had a slight effect on increasing the percentage saving in annual cooling EUI. In present climate, increasing the canopy cover from $20 \%$ (S5) to $36 \%$ (S4) (in the 'area under development') has resulted in increasing the saving percentage by $0.51 \%$ and $0.87 \%$ in case of changeover and concurrent mixed-mode cooling respectively. Further increase in canopy cover (from $36 \%$ (S4) to $79 \%$ (S3)) has resulted in increasing the saving percentage by an additional $0.34 \%$ and $0.53 \%$ in case of changeover and concurrent mixed-mode cooling respectively. In future climate, the increases in annual cooling EUI saving percentage are $0.12 \%$ and $0.24 \%$ in case of changeover and concurrent mixed-mode cooling respectively (when increasing canopy cover from $20 \%$ (S5) to $36 \%$ (S4)) and $0.37 \%$ and $0.13 \%$ in case of changeover and concurrent mixed-mode cooling respectively (when increasing canopy cover from $36 \%$ (S4) to $79 \%$ (S3)).

\section{Synergistic Energy Saving Potential of GBI}

Table 5 shows the results of group 3 simulation scenarios (S6, S7 and S8) that represent combining GI and BI (53\% green cover and $47 \%$ water cover in the 'area under development'). These results indicate that combining GI and BI (GBI) can reduce the annual cooling EUI, on average, by $6.73 \%$ with a maximum reduction of $10.84 \%$. The results also reveal that the annual cooling EUI 
savings are mainly influenced by the presence of water since increasing the canopy cover had a minor effect in increasing the reduction of annual cooling EUI.

Table 5: Simulation results for the GBI scenarios.

\begin{tabular}{|c|c|c|c|c|}
\hline & Scenario & $\begin{array}{l}\text { Cooling EUI } \\
\left(\mathbf{k W h} / \mathrm{m}^{2}-\mathrm{yr}\right)\end{array}$ & $\begin{array}{c}\text { Cooling EUI } \\
\text { Savings } \\
\left(\mathrm{kWh} / \mathrm{m}^{2}-\mathrm{yr}\right)\end{array}$ & $\begin{array}{c}\text { \%age } \\
\text { Saving }\end{array}$ \\
\hline \multirow{10}{*}{ 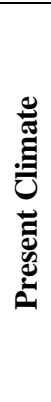 } & \multicolumn{4}{|c|}{ Changeover Mixed-Mode Cooling } \\
\hline & Baseline & 30.77 & - & - \\
\hline & S6 & 28.07 & 2.70 & $8.77 \%$ \\
\hline & S7 & 28.33 & 2.43 & $7.91 \%$ \\
\hline & S8 & 28.35 & 2.42 & $7.85 \%$ \\
\hline & \multicolumn{4}{|c|}{ Concurrent Mixed-Mode Cooling } \\
\hline & Baseline & 37.69 & - & - \\
\hline & S6 & 33.60 & 4.09 & $10.84 \%$ \\
\hline & S7 & 33.72 & 3.96 & $10.52 \%$ \\
\hline & S8 & 33.96 & 3.72 & $9.88 \%$ \\
\hline \multirow{10}{*}{ 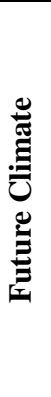 } & \multicolumn{4}{|c|}{ Changeover Mixed-Mode Cooling } \\
\hline & Baseline & 85.19 & - & - \\
\hline & S6 & 81.89 & 3.30 & $3.87 \%$ \\
\hline & S7 & 81.98 & 3.21 & $3.77 \%$ \\
\hline & S8 & 82.01 & 3.17 & $3.72 \%$ \\
\hline & \multicolumn{4}{|c|}{ Concurrent Mixed-Mode Cooling } \\
\hline & Baseline & 149.65 & - & - \\
\hline & S6 & 142.80 & 6.85 & $4.57 \%$ \\
\hline & S7 & 142.89 & 6.76 & $4.52 \%$ \\
\hline & S8 & 142.93 & 6.72 & $4.49 \%$ \\
\hline
\end{tabular}

In the present climate, increasing the canopy cover from $20 \%$ (S8) to $36 \%$ (S7) (in the 'area under development') has resulted in increasing the percentage saving by $0.06 \%$ in case of changeover mixed-mode cooling and by $0.64 \%$ in case of concurrent mixed-mode cooling. Increasing the canopy cover from $36 \%$ (S7) to $79 \%$ (S6) has resulted in an additional increase in the saving percentage by $0.86 \%$ and $0.32 \%$ in case of changeover and concurrent mixedmode cooling respectively. In the future climate, the increases are reduced where increasing the canopy cover from $20 \%$ (S8) to $36 \%$ (S7) can reduce the saving percentage by $0.05 \%$ and $0.03 \%$ in case of changeover and concurrent mixed-mode cooling respectively. When the canopy cover is further increased (from $36 \%$ (S7) to $79 \%$ (S6)), this leads to an additional increase in the saving percentage by $0.1 \%$ and $0.05 \%$ in case of changeover and concurrent mixed-mode cooling respectively.

\section{Impact of Climate Change}

By averaging the results of all the simulation scenarios (Table 3, Table 4 and Table 5) according to the climate scenario (present and future), it appears that the climatic conditions of the future can increase the annual cooling EUI, on average, by $253.96 \%$ (188.82\% and $319.1 \%$ in case of changeover and concurrent mixed-mode cooling respectively). Also, averaging the results of group 1 (BI) , 2 (GI) and 3 (GBI) simulation scenarios in present and future (as shown in Figure 6) reveals that climate change can has a negative impact on the effect of BI, GI and GBI in reducing the annual cooling EUI and can decrease their percentage saving in annual cooling EUI by $5.97 \%$, $3.45 \%$ and $4.39 \%$ respectively when changeover mixed- mode cooling is applied and by $6.53 \%, 4.7 \%$ and $5.88 \%$ respectively when concurrent mixed-mode cooling is used.

Changeover Mixed-Mode Cooling

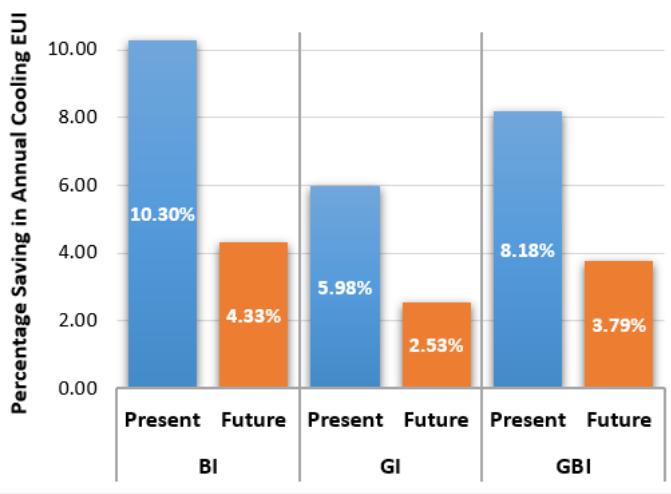

Concurrent Mixed-Mode Cooling

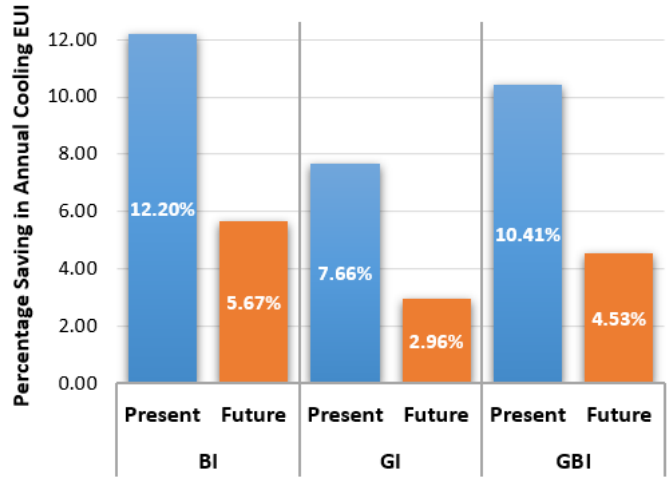

Figure 6: Climate change impact on the energy saving potential of BI, GI and GBI.

\section{Impact of Mixed-Mode Cooling}

Averaging the results of all the simulation scenarios (Table 3, Table 4 and Table 5) according to the mixedmode cooling strategy used indicates that using a concurrent mixed-mode cooling can increase the annual cooling EUI, on average, by $47.31 \%$ (20.2\% in present climate and $74.41 \%$ in future climate) when compared to the changeover mixed-mode cooling. Also, it is clear that the mixed-mode cooling strategy applied at the building scale can impact the effect of BI, GI and GBI (as shown in Figure 6) where applying a concurrent mixed-mode cooling strategy can increase their percentage saving in annual cooling EUI by $1.9 \%, 1.68 \%$ and $2.23 \%$ respectively in present climatic conditions and by $1.34 \%$, $0.43 \%$ and $0.74 \%$ respectively in future climatic conditions when compared to applying a changeover mixed-mode cooling.

\section{Conclusion}

This study employed a coupled simulations methodology by coupling the EnergyPlus building energy model, ENVI-met microclimate model, and the climate change models of IPCC AR5 to a case study in Alexandria, Egypt. The aim was to simulate the urban microclimatic changes induced by GBI and its effect on the annual cooling energy use of residential buildings in present and future 
climates given different mixed-mode cooling strategies applied at the building scale. Eight different scenarios (in addition to a baseline scenario) that represent BI, GI, and GBI were simulated in the study. The key findings of this study can be summarized in the following points:

- Using BI alone has the highest average cooling energy use savings $(8.12 \%)$ followed by GBI $(6.73 \%)$ and GI $(4.78 \%)$.

- Increasing the canopy cover has a negligible impact on increasing the cooling energy use savings both when GI is applied alone or in combination with BI.

- Increasing the water cover has a good potential for increasing the cooling energy use savings by BI.

- In the case of GBI, the cooling energy use reduction effect is mainly controlled by the presence of $\mathrm{BI}$.

- The cooling energy use reduction effect of BI, GI and GBI will remain until the end of the century (2081 2100) but the effect will be reduced.
- Using a concurrent mixed-mode cooling strategy can increase the annual cooling EUI saving percentages of $\mathrm{BI}, \mathrm{GI}$ and GBI when compared to changeover.

Therefore, the study recommends that the utilization of BI should be the first option in planning a sustainable and resilient city that reduces its dependence on energy. However, if the utilization of BI is not feasible (e.g. due to the construction costs or space constraints), the use of GI can be the second option. While combining GI and BI might be useful for aesthetics and human well-being, it is not recommended, from an energy saving point of view since it will not result in a significant difference in energy savings compared to the use of GI alone and at the same time will be worse than the use of BI alone. The study also recommends that great attention must be paid to the mixed-mode cooling strategy applied at the building scale since it can greatly affect the cooling energy use of the building and the effect of BI, GI, or GBI on reducing that use.

\begin{tabular}{|c|c|c|c|c|}
\hline \multicolumn{2}{|c|}{$\begin{array}{c}\text { Scenario 0 } \\
\text { (Baseline) }\end{array}$} & \multicolumn{3}{|c|}{ Group 2} \\
\hline \multicolumn{2}{|c|}{ El-Mahmoudia canal is covered by an asphalt road. } & $\begin{array}{l}\text { El-Mahmoudia canal is } \\
\text { covered by a green } \\
\text { space (grass }+ \text { trees } 6 \mathrm{~m} \\
\text { apart). }\end{array}$ & $\begin{array}{l}\text { El-Mahmoudia canal is } \\
\text { covered by a green } \\
\text { space (grass }+ \text { trees } 9 \mathrm{~m} \\
\text { apart). }\end{array}$ & $\begin{array}{l}\text { El-Mahmoudia canal is } \\
\text { covered by a green } \\
\text { space (grass + trees } 12 \\
\text { m apart). }\end{array}$ \\
\hline \multicolumn{2}{|c|}{$\begin{array}{c}\text { Area Under Development } \\
\text { Water Cover }=0 \% * \\
\text { Green Cover }=0 \% * \\
\text { Canopy Cover }=0 \% * *\end{array}$} & $\begin{array}{c}\text { Area Under Development } \\
\text { Water Cover }=0 \% \\
\text { Green Cover }=100 \% \\
\text { Canopy Cover }=79 \%\end{array}$ & $\begin{array}{c}\text { Area Under Development } \\
\text { Water Cover }=0 \% \\
\text { Green Cover }=100 \% \\
\text { Canopy Cover }=36 \%\end{array}$ & $\begin{array}{c}\text { Area Under Development } \\
\text { Water Cover }=0 \% \\
\text { Green Cover }=100 \% \\
\text { Canopy Cover }=20 \%\end{array}$ \\
\hline \multicolumn{2}{|c|}{ Group 1} & Scenario 6 (S6) & Group 3 & Scenari \\
\hline $\begin{array}{l}\text { The existing site with } \\
\text { no modifications. }\end{array}$ & $\begin{array}{l}\text { The width of El- } \\
\text { Mahmoudia canal is } \\
\text { increased (from } 33 \mathrm{~m} \text { to } \\
66 \mathrm{~m} \text { ). }\end{array}$ & $\begin{array}{l}\text { El-Mahmoudia canal is } \\
\text { surrounded by a green } \\
\text { space (grass + trees } 6 \mathrm{~m} \\
\text { apart). }\end{array}$ & $\begin{array}{l}\text { El-Mahmoudia canal is } \\
\text { surrounded by a green } \\
\text { space (grass + trees } 9 \mathrm{~m} \\
\text { apart). }\end{array}$ & $\begin{array}{l}\text { El-Mahmoudia canal is } \\
\text { surrounded by a green } \\
\text { space (grass + trees } 12 \\
\text { m apart). }\end{array}$ \\
\hline $\begin{array}{c}\text { Area Under Development } \\
\text { Water Cover }=47 \% \\
\text { Green Cover }=0 \% \\
\text { Canopy Cover }=0 \%\end{array}$ & $\begin{array}{c}\text { Area Under Development } \\
\text { Water Cover }=100 \% \\
\text { Green Cover }=0 \% \\
\text { Canopy Cover }=0 \%\end{array}$ & $\begin{array}{c}\text { Area Under Development } \\
\text { Water Cover }=47 \% \\
\text { Green Cover }=53 \% \\
\text { Canopy Cover }=79 \%\end{array}$ & $\begin{array}{c}\text { Area Under Development } \\
\text { Water Cover }=47 \% \\
\text { Green Cover }=53 \% \\
\text { Canopy Cover }=36 \%\end{array}$ & $\begin{array}{c}\text { Area Under Development } \\
\text { Water Cover }=47 \% \\
\text { Green Cover }=53 \% \\
\text { Canopy Cover }=20 \%\end{array}$ \\
\hline
\end{tabular}

Figure 7: Simulation scenarios tested in the study. 


\section{References}

Attia, S., Evrard, A. and Gratia, E. (2012). Development of benchmark models for the Egyptian residential buildings sector. Applied Energy 94(2012), 270-284.

Attia, S. and Herde, A. (2009). Impact and Potentials of Community Scale Low-Energy Retrofit: Case Study in Cairo. Proceedings from the 3rd CIB International Conference on Smart and Sustainable Built Environment. Delft (Netherlands), 15-19 June 2009.

Bartesaghi Koc, C., Osmond, P. and Peters, A. (2018). Evaluating the cooling effects of green infrastructure: A systematic review of methods, indicators and data sources. Solar Energy 166(2018), 486-508.

Brager, G. (2006). Mixed-Mode Cooling. ASHRAE Journal 48(August 2006), 30-37.

CEIC Data (2017). Egypt Electricity Consumption (Household). Available from https://www.ceicdata.com/en/egypt/electricityconsumption/electricity-consumption-commercialand-domestic-household [accessed 14 October 2018].

Daly, A. (2002). Operable Windows and HVAC Systems. HPAC Engineering (December), 22-30.

Day, A.R., Knight, I., Dunn, G. and Gaddas, R. (2003). Improved methods for evaluating base temperature for use in building energy performance lines. Building Services Engineering Research and Technology 24(4), 221-228.

DEBE (2011). Database of Egyptian Building Envelopes. Available from http://www.shadyattia.net/research/DEBE/index.html [accessed 23 December 2018].

DesignBuilder (2018). DesignBuilder Website. Available from https://designbuilder.co.uk/ [accessed 25 December 2018].

Dickinson, R. and Brannon, B. (2016). Generating Future Weather Files for Resilience. Proceedings from PLEA 2016: $32^{\text {nd }}$ International Conference on Passive and Low Energy Architecture. Los Angeles (USA), 11-13 July 2016.

Elwy, I., Ibrahim, Y., Fahmy, M. and Mahdy, M. (2018). Outdoor microclimatic validation for hybrid simulation workflow in hot arid climates against ENVI-met and field measurements. Energy Procedia 153(2018), 29-34.

EnergyPlus (2018a). EnergyPlus Version 9.0.1 Documentation. Available from https://energyplus.net/documentation [accessed 17 December 2018].

EnergyPlus (2018b). EnergyPlus Weather Data. Available from https://energyplus.net/weather [accessed 18 December 2018].

ENVI-met (2018). ENVI-met Technical Documentation. Available from http://envi-met.info/doku.php [accessed 18 December 2018].
Fahmy, M., El-Hady, H., Mahdy, M. and Abdelalim, M.F. (2017). On the green adaptation of urban developments in Egypt; predicting community future energy efficiency using coupled outdoor-indoor simulations. Energy and Buildings 153, 241-261.

Fahmy, M., Kamel, H., Mokhtar, H., Elwy, I., Gimiee, A., Ibrahim, Y. and Abdelalim, M. (2019). On the Development and Optimization of an Urban Design Comfort Model (UDCM) on a Passive Solar Basis at Mid-Latitude Sites. Climate 7(1), 1-28.

Fahmy, M., Mahdy, M.M. and Nikolopoulou, M. (2014). Prediction of future energy consumption reduction using GRC envelope optimization for residential buildings in Egypt. Energy and Buildings 70, 186193.

Fumo, N. (2014). A review on the basics of building energy estimation. Renewable and Sustainable Energy Reviews 31(2014), 53-60.

Heijden, J. (2014). Governance for Urban Sustainability and Resilience: Responding to Climate Change and the Relevance of the Built Environment. Edward Elgar Publishing Limited. Gloucestershire (UK).

IBPSA-USA (2012). BEMBook wiki: Energy Modeling Methodology (Comparison vs. Prediction). Available from http://bembook.ibpsa.us/index.php/Comparison_vs._ Prediction [accessed 20 January 2019].

Dulac, J., LaFrance, M., Trudeau, N. and Yamada, H. (2013). Transition to Sustainable Buildings: Strategies and opportunities to 2050. IEA Publications. Paris (France).

IPCC (2001). Climate Change 2001: Synthesis Report. Contribution of Working Groups I, II and III to the Third Assessment Report of the Intergovernmental Panel on Climate Change. Cambridge University Press. Cambridge (United Kingdom).

IPCC (2014). Climate Change 2014: Synthesis Report. Contribution of Working Groups I, II and III to the Fifth Assessment Report of the Intergovernmental Panel on Climate Change. IPCC. Geneva (Switzerland).

Kottek, M., Grieser, J., Beck, C., Rudolf, B. and Rubel, F. (2006). World Map of the Köppen-Geiger climate classification updated. Meteorologische Zeitschrift 15(3), 259-263.

Morakinyo, T.E., Lau, K.K.-L., Ren, C. and Ng, E. (2018). Performance of Hong Kong's common trees species for outdoor temperature regulation, thermal comfort and energy saving. Building and Environment 137, 157-170.

Perini, K. (2016). Green and Blue Infrastructure in Cities. In Perini, K., Sabbion, P. Urban Sustainability and River Restoration. John Wiley \& Sons Ltd. West Sussex (UK). 
Radhi, H., Sharples, S. and Assem, E. (2015). Impact of urban heat islands on the thermal comfort and cooling energy demand of artificial islands - A case study of AMWAJ Islands in Bahrain. Sustainable Cities and Society 19, 310-318.

Scott, J. (2007). Canopy Cover Definition. Available from http://www.firewords.net/definitions/canopy_cover.h tm [accessed 19 January 2019].

Wang, Y., Bakker, F., de Groot, R. and Wörtche, H. (2014). Effect of ecosystem services provided by urban green infrastructure on indoor environment: A literature review. Building and Environment 77, 88100.
Yasser, A. (2017). The Role of Trees in Improving Thermal Comfort and Mitigating Urban Heat Island: Envi-met Simulation Study of An Urban Model in Cairo City (Unpublished master's dissertation). Cairo University. Cairo (Egypt).

Zhang, A., Bokel, R., van den Dobbelsteen, A., Sun, Y., Huang, Q. and Zhang, Q. (2017). An integrated school and schoolyard design method for summer thermal comfort and energy efficiency in Northern China. Building and Environment 124, 369-387.

Zhang, L., Zhan, Q. and Lan, Y. (2018). Effects of the tree distribution and species on outdoor environment conditions in a hot summer and cold winter zone: A case study in Wuhan residential quarters. Building and Environment 130(September 2017), 27-39. 